\title{
Targeting Epigenetic Mechanisms: Potential of Natural Products in Cancer Chemoprevention
}

Author

Affiliation
Alexander-Thomas Hauser, Manfred Jung

Institute of Pharmaceutical Sciences, University of Freiburg, Freiburg, Germany
Key words

- Epigenetics

- histone modifications

- DNA methylation

- histone acetylation received April 11, 2008

revised June 6,2008

accepted June 20, 2008

Bibliography

DOI $10.1055 / \mathrm{s}-2008-1081347$

Planta Med 2008; 74: 1593-

1601

(c) Georg Thieme Verlag KG

Stuttgart · New York

Published online August 14,

2008

ISSN 0032-0943

\section{Correspondence}

Prof. Dr. Manfred Jung

Institute of Pharmaceutical

Sciences

Albertstr. 25

79104 Freiburg

Germany

Tel.: +49-761-203-4896

Fax: +49-761-203-6321

manfred.jung@pharmazie.uni-

freiburg.de

\section{Abstract \\ $\nabla$}

The term epigenetics is defined as heritable changes in gene expression patterns that occur without changes in DNA sequence. Epigenetic changes according to this definition are achieved by methylation of cytosine bases in the DNA and by histone modifications, such as acetylation, methylation or phosphorylation. These modifications play an important role in regulating gene expression and the existence of an epigenetic code which maintains these modifications even

\section{Introduction}

$\nabla$

According to Crick and his "Central Dogma of Molecular Biology” [1] from 1970, DNA was supposed to be the only source of genetic information, running fluently from DNA to RNA and finally to proteins. But by now, many phenomena are known which cannot be explained by this "central dogma". It is remarkable that a single mammalian genome encoding about 30,000 genes is able to express different gene patterns in about 200 different cell types at different stages of development [2]. The function and morphology of liver cells, for example, differs completely from those of neural cells, although they have the same set of genes, and most importantly, this phenotype is maintained upon every division of the cells. So it is obvious that there has to be an additional layer of information encoded in or around the genome exceeding the information of the genetic sequence. This additional level of information is achieved by epigenetic modifications which in their entirety are called the epigenome (from the Greek prefix epi-, which means "on" or "over"). In 1999, Wolffe et al. defined the term "epigenetics" as "heritable changes in gene expression that occur without changes in DNA sequence" [3]. These heritable changes are ach- upon cell division has been underlined by many investigations. Targeting the enzymes which catalyze DNA methylation or histone modifications may be a possibility not only for cancer therapy but also for chemoprevention since disruption of epigenetic balance is known to cause diseases such as cancer. In this review, we want to present the key epigenetic targets. We highlight natural products that modulate these epigenetic mechanisms and show their potential for cancer chemoprevention. ieved by methylation of cytosine bases in the DNA and by post-translational histone modifications, such as acetylation, methylation or phosphorylation. Epigenetic events occur throughout all stages of tumorigenesis and are accepted as important mechanisms in silencing tumor suppressor genes. Therefore, they are a key driving force in the development of cancer. We present here the major epigenetic targets and mechanisms of biological effects for inhibitors and their relationship to human cancer. We present inhibitors from natural sources and mainly focus on those which are of interest for cancer chemoprevention. Compounds like vitamins that also act rather remotely on epigenetic phenomena as well [4] will not be included. In most cases only links to cancer therapy are documented so far and we discuss selected examples with regard to that as well.

\section{DNA Methylation \\ $\nabla$}

The methylation of cytosine bases in the mammalian genome by DNA methyltransferases occurs at cytosines located $5^{\prime}$ to a guanosine as part of a $\mathrm{CpG}$ dinucleotide and in total about $70-80 \%$ of the CpG sites are methylated [4], [5], 
[6]. CpG dinucleotides are found in short DNA regions with a length of $0.5-4 \mathrm{~kb}$, which are known as $\mathrm{CpG}$ islands and which are located in the proximal promoter regions of about half of the genes in our genome. They represent about $1-2 \%$ of the genome and contain more than half of the unmethylated CpG sites [4], [5], [7], [8]. Other highly methylated sequences include satellite DNAs, repetitive elements, non-repetitive intergenic DNA and exons of genes [9]. In cancer cells the hypermethylation of certain promoter regions is known as one of the most important epigenetic changes taking place in tumors, leading to transcriptional silencing of tumor suppressor genes [10], [11], [12]. A large variety of genes are aberrantly methylated in cancer cells including genes that are involved in regulating DNA repair (e.g., BRCA1, MLH1), signal transduction (e.g., RASSF1), cell cycle (e.g., p16 $\left.{ }^{\mathrm{INK} 4 \mathrm{a}}, \mathrm{p} 15^{\mathrm{INK} 4 \mathrm{~b}}\right)$, carcinogen metabolism (e.g., GSTP1), cell adherence (e. g., CDH1, CDH13), apoptosis (e.g., DAPK1, TMS1) or angiogenesis (e.g., THBS1) [11], [12]. But of course, DNA methylation is also an essential function in normal mammalian cells. It is involved in genomic imprinting (restriction of the expression of a gene to only one of the two parental chromosomes) [13] which is important for development. It is also necessary for Xchromosomal gene inactivation [14], the mechanism of dosage compensation in female mammals. The importance of DNA methylation for normal genome function could be shown by the finding that a homozygous mutation of the DNA methyltransferase gene results in embryonic lethality [15]. Thus, unwanted activation of certain genes by DNA methyltransferase inhibitors may pose a risk, e.g., by derepression of proinvasive genes [16]. DNA methyltransferases (DNMTs) use S-adenosyl--Lmethione (SAM) as methyl group donating cofactor. So far, four DNMTs are known in mammals, called DNMT1, DNMT2, DNMT3A and DNMT3B [17], [18], [19].

\section{Histone Modifications}

$\nabla$

The structure of chromatin plays an important role in gene expression. Chromatin is a macromolecular complex existing of DNA, histone and non-histone proteins, and is responsible for the controlled storage of the genetic information within the nucleus [20]. The basic repeating units of chromatin are the nucleosomes that consist of $147 \mathrm{bp}$ of DNA wrapped around a histone octamer, which is composed of an $\mathrm{H} 3 / \mathrm{H} 4$ tetramer and two H2A/ $\mathrm{H} 2 \mathrm{~B}$ dimers [21]. This alignment of nucleosomes is compacted into a fiber of $30 \mathrm{~nm}$, which is then further condensed to form the chromosomes. This higher order folding is stabilized by the linker histone H1 [22]. There are different levels of chromatin organization and subsequently transcriptional activity. Usually condensed, inaccessible chromatin ("heterochromatin") mediates transcriptional repression, while transcriptionally active genes are in regions of the more open and accessible "euchromatin" [23]. Importantly, histones have amino-terminal tails protruding out of the nucleosomes. These tails are open for posttranslational modifications, such as acetylation, methylation, phosphorylation, sumoylation and ubiquitination. [24] To this date at least eight different histone modifications, taking place mainly at the $\mathrm{N}$-terminal histone tails of histone $\mathrm{H} 3$ and histone H4, have been documented [25]. These modifications result in changes in the accessibility of the DNA to transcription factors and in protein interactions determining the chromatin structure [26]. So, chromatin is highly dynamic and can change its structure in response to cellular signals, which in turn affects gene ex- pression [27]. Because of the diverse and complex nature of histone modifications, which interact with each other, the term "histone code" has been coined. The modifications of histone proteins are also linked with DNA methylation, as DNA methyltransferases recruit histone deacetylases (HDACs), leading to histone deacetylation and subsequently to transcriptional repression.

Several in vitro studies have shown the cooperation of DNA methylation and histone deacetylation in order to repress transcription [28], [29]. Therefore, it is not surprising that the combination of DNMT and HDAC inhibition has been shown to induce differentiation, apoptosis and cell growth arrest in several cancer cell lines [30]. This synergistic effect is seen in the increase in expression of specific cancer-related genes. For example, the re-expression of the hypermethylated genes MLH1, TIMP3, CDKN2B and CDKN2A was greatly enhanced when histone deacetylase inhibitors were combined with low doses of an inhibitor of DNA methyltransferases, whereas HDAC inhibition alone was not able to reactivate transcription [31]. The expression of the cyclooxygenase 2 gene, whose promoter is hypermethylated in gastric cancer cells, can be restored with a combined treatment of DNMT and HDAC inhibitors, while DNMT inhibition itself only induces partial re-expression [32]. More links between the "histone code" and the "cytosine methylation code" are becoming evident [33].

Certain post-translational modifications on distinct amino acids in the N-terminal tails of histones have been linked to either active or repressed transcription. The acetylation of certain lysine residues by histone acetyltransferases (HATs), for example, is associated with transcriptionally active regions, whereas transcriptionally repressed chromatin usually is hypoacetylated [34]. But there are also examples where histone hyperacetylation has been shown to lead to gene repression [35]. For other modifications on the histone tails examples have been provided for both activators and inhibitors of transcription. The methylation of lysine residues leads either to transcriptional activation or repression, depending on the site of lysine methylation [36]. As there are different states of methylation (mono-, di- or trimethylation) possible for one lysine residue, the biological consequences of methylation may differ [37]. Although the whole process of selection of histone marks along our genome is not fully understood, it is obvious that the enzymes, which catalyze post-translational histone modifications, are actively involved in carcinogenesis. It has been shown that global loss of monoacetylation and trimethylation of histone $\mathrm{H} 4$ is a common hallmark of human tumor cells [38]. Another example is the correlation of phosphorylated H3T11 with Gleason scores of prostate carcinomas [39].

\section{Epigenetic Targets and their Inhibitors \\ $\nabla$}

\section{DNA methyltransferases}

In contrast to those tumor suppressor genes which are inactivated by genetic alterations, the genes that are silenced due to epigenetic modifications are still intact and can be reactivated by intervention of small molecules acting as modifiers of epigenetic mechanisms. For example, many genes that are hypermethylated in cancer can be reactivated with inhibitors of DNA methyltransferases [40]. Several DNA methyltransferase inhibitors have been developed so far. Analogues of cytidine, such as 5-azacytidine or 5-aza-2'-deoxycytidine have long been known for their 
ability of inhibiting DNA methyltransferases [40], [41]. Several studies have shown the ability of DNA methyltransferase inhibitors to prevent cancer using different pathways [42], [43], [44], [45]. There are also some natural products that were identified as inhibitors of DNA methyltransferases, thus having potential in preventing cancer, too. For example, some disulfide bromotyrosine derivatives, such as psammaplin A, isolated from the sponge Pseudoceratina purpurea, were found to be potent inhibitors of DNMT1 but also histone deacetylases [46]. (-)-Epigallocatechin 3-gallate (EGCG), a main polyphenol from green tea, inhibits DNA methyltransferases and can thereby reactivate silenced genes like P16 $6^{\mathrm{INK} 4 \mathrm{a}}$ and $h M L H 1$ in tumor cells [47]. EGCG is a pleiotropic drug that has received a lot of attention for cancer chemoprevention but it remains to be determined which of its biological activities are the most important for its preventive abilities [48]. Two other polyphenols from coffee, caffeic acid and chlorogenic acid, have also been reported to be inhibitors of DNMT1 in the low micromolar range [49] and also apple polyphenols have similar activity [50]. The major isoflavone from soy bean, genistein, has been reported to prevent cancer in animal models [51]. The effects of genistein have been studied in different cancer cell lines, where it was able to inhibit cancer cell growth [52], to induce apoptosis and cell cycle arrest and to inhibit angiogenesis [53], [54], but the exact mechanisms behind these effects are not fully understood so far. Several mechanisms, such as estrogenic and antiestrogenic effects, are discussed to explain this activity, but one possible mechanism of particular interest is the regulation of transcriptional activity by modulating DNA methylation. Genistein inhibits methylation of DNA and thus can lead to re-expression of methylation-silenced genes, such as RAR $\beta, p 16 I N K 4$ and MGMT in the esophageal squamous cell carcinoma cell line KYSE 510 [55]. As the histone acetylation status is also known to have an impact on the re-expression of these genes, the weak inhibition of histone deacetylase activity observed after treatment of the cells with genistein is possibly contributing to the gene reactivation, too. Biochanin A and daidzein, two other isoflavones, are weaker inhibitors of DNMTs and as they also are less effective in reactivating the $R A R \beta$ gene, a direct correlation between the inhibition of DNA methyltransferases and the reactivation of the silenced genes can be assumed [55].

\section{Reversible histone acetylation}

The steady state of reversible protein acetylation is maintained by a dynamic equilibrium between histone acetyltransferases (HATs) and histone deacetylases (HDACs). The effect of these chromatin modifying enzymes on gene expression has been studied widely. In 1964, Allfrey was the first to suggest that acetylation of histones was involved in regulation of transcription [56]. HAT enzymes can be classified into several groups, including the GNAT family (e.g., GCN5, PCAF), the MYST group (e.g., Tip60), the p300/CBP family, the SRC group and the TAFII250 family [57]. The histone deacetylases can be divided into four classes [58]. The HDACs of class I, which have homology to the yeast HDAC Rpd3 [59], are located in the nucleus, where they interact with transcriptional repressors and cofactors. This class I includes HDAC1, HDAC2, HDAC3 and HDAC8 [60]. HDAC11 was first classified as a class I enyzme but lately is attributed a class of its own (class IV HDAC [61]). The HDACs of class II are able to shuttle between the cytoplasm and the nucleus and show homology to the yeast deacetylase HdaI [62]. Class II histone deacetylases include HDAC4, HDAC5, HDAC6, HDAC7, HDAC9 and HDAC10. Interestingly, one of these deacetylases, HDAC6 has two catalytic domains, one for histone deacetylation, one for deacetylation of tubulin [63], showing that HDACs, as well as HATs, also target non-histone protein substrates. The histone deacetylases of classes I, II and IV have a zinc ion at the base of their catalytic pocket and a hydrophobic pocket that allows the acetylated lysine residue to insert.

The third class of histone deacetylases is called Sirtuins after their homology to the yeast silent information regulator 2 (Sir2) [64], [65], [66]. They differ completely from the zinc-dependent HDACs of classes I, II and IV in their mode of action in removing the acetyl group from lysine residues, as they are dependent on nicotinamine adenine dinucleotide $\left(\mathrm{NAD}^{+}\right)$. For class III HDACs also a large number of non-histone substrates, such as p53 or tubulin have been reported [65], [66], [67].

\section{Modulators of histone deacetylases}

The first inhibitors of histone deacetylases classes I and II were isolated from natural sources and based upon those, a variety of synthetic inhibitors have been developed. The general structure contains a binding region responsible for enzyme specifity, which is separated by a spacer from a group that effects inactivation of the enzyme [68], [69]. This inactivating group needs to be able to bind the zinc ion in the active site, often referred to as the zinc binding group (ZBG). The HDAC inhibitors are classified into different groups depending on their structure, including (a) small-chain fatty acids, (b) hydroxamic acids, (c) cyclic tetrapeptides, (d) benzamides and others that do not fit in these classifications [70], [71].

The largest of these groups of HDAC inhibitors is that which carries a hydroxamic acid as the zinc binding group with the natural product trichostatin A (TSA) as lead structure (see $\bullet$ Fig. 1 for selected inhibitor structures). TSA, isolated from Streptomyces hygroscopicus, inhibits HDACs of group I and group II in the nanomolar range and induces differentiation, cell cycle arrest and apoptosis [72]. It has been reported that HDAC inhibition can affect changes in gene expression of genes that have an impact on apoptosis and the cell cycle, such as $\mathrm{p} 21^{\mathrm{Cip} 1 / \text { Waf1 }}$, cyclins (A, E, B1, D1 and D3), apoptosis mediators (e.g., CD95, Bax, Bcl2), transcription factors (e.g., GATA-2, c-Myc) and retinoic acid receptors (RAR) [73], [74].

Acute promyeolocytic leukemia (APL) is one disease of particular interest concerning RAR as targets of retinoids, as APL patients respond with disease remission, when treated with pharmacological doses of retinoic acid. In APL, the RAR/PML oncogenic transcription factor binds to the retinoic acid response element (RARE), recruiting the CoR/SIN3/HDAC complex and repressing transcription. Agonists, such as retinoic acid, displace CoR/SIN3/ HDAC by interacting with the RAR and thereby activate gene expression in association with HATs [71]. Therefore, it is apparent that the therapeutic efficacy in cases of APL can be improved, when synthetic or naturally occurring retinoids are combined with inhibitors of histone deacetylases [75].

Inhibitors of HDACs are able to disrupt the cell cycle in the $\mathrm{G}_{2}$ phase, so that the cells enter the M phase prematurely and furthermore they have been reported to interfere directly with the mitotic spindle checkpoint [76]. Cell cycle arrest and/or apoptosis are induced by the activation of repressed genes, such as P21 and $B A X$. Strikingly, tumor cells seem to be more sensitive to the actions of HDAC inhibitors than normal cells. The mechanisms behind this "cancer selectivity" are not fully understood, but it has been reported that thioredoxin, the intracellular thiol status and the accumulation of reactive oxygen species as well as the 
<smiles>CC(/C=C/C(=O)NO)=C\C(C)C(=O)c1ccc(N(C)C)cc1</smiles>

Trichostatin A<smiles>C=CCSSCC=C</smiles>

Diallyl disulfide<smiles>CS(=O)CCCCN=S</smiles><smiles>CS(=O)CCCCNC(=S)SC[C@H](N)C(=O)O</smiles>

Sulforaphane<smiles>C=CCSSC[C@H](N)C(=O)O</smiles>

S-Allylmercaptocysteine

Sulforaphane cysteine<smiles>CCCC(CCC)C(=O)Oc1ccc(-c2cc(=S)ss2)cc1</smiles>

ACS 2<smiles>COc1cc(/C=C/C(=O)/C=C(O)/C=C/c2ccc(O)c(OC)c2)ccc1O</smiles>

Curcumin

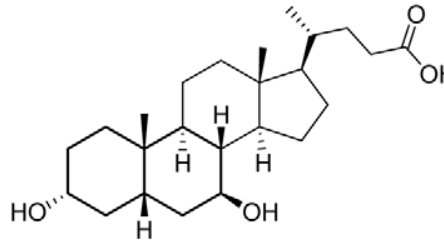

Ursodeoxycholic acid

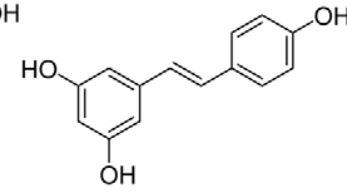

Resveratrol
Fig. 1 Structures of important epigenetic modifiers.

induction of TRAIL, DR4 and DR5 could be responsible for it [77], [78]. Some HDAC inhibitors have been reported to be able to lead to an increasing level of CD95/CD95 L [79] and FAS/FASL [80], consequently leading to receptor-mediated apoptosis. HDACs interact directly with the tumor suppressor protein $\mathrm{p} 53$ by removing acetyl groups from its C-terminal tail, resulting in decreased transactivation and on the other hand, HDAC inhibitors can lead to an increase in acetylation levels of the $p 53$ gene and therefore to an increase of transcriptional activity [71].

So far, there are several studies that have tried to point out the chemopreventive potential of HDAC inhibitors [81], [82], [83]. For example, suberoylanilide hydroxamic acid (SAHA), a synthetic inhibitor of zinc-dependent HDACs, decreases the incidence of $N$-methyl- $N$-nitrosourea-induced rat mammary tumors and the multiplicity of carcinogen-induced lung tumors in mice [83]. SAHA (INN: Vorinostat, Zolinza ${ }^{\mathrm{TM}}$ ) has been approved for the treatment of cutaneous T-cell lypmphoma by the FDA [84]. Although inhibitors of histone deacetylases have a direct impact on tumor cells, it is discussed that interaction with the cancer cell environment also plays a role in chemoprevention. In case of metastasis, for example, the primary tumor needs vasculari- zation to supply nutrients and oxygen, before it is able to finally metastasize. Hypoxia, one of the factors inducing angiogenesis, is known to increase expression levels and activity of HDAC1 [85] and therefore it has been hypothesized and already been demonstrated that inhibition of HDAC1 can lead to inhibition of angiogenesis in vitro and in vivo [86]. Another pathway leading to cancer prevention is the up-regulation of stimulary factors of the immune system. HDAC inhibition induces expression of CD40, CD80 and CD86, as well as major histocompatibility (MHC) proteins of class I and class II and interferons [71], thus making it more difficult for tumor cells to survive.

Remarkably, HDAC inhibitors have a large variety of targets in different stages of tumorigenesis and therefore are promising candidates both in therapy and in prevention of cancer. Therefore, it is not surprising that there are several HDAC inhibitors in clinical trials, tested against different kinds of tumors [87]. Among them is the natural product FK-228 (also known as FR90122 or depsipeptide) which is in clinical trials for the treatment of cancer (INN: romidepsin) [88]. Some natural products that have been reported to have potential in cancer prevention acting as inhibitors of histone deacetylases shall be discussed in the following.

Butyrate, a short-chain fatty acid, which inhibits HDAC activity at high micromolar concentrations, is formed in the digestive tract by fermentation of dietary fiber. Butyrate affects different signalling pathways [89], [90], suggesting multiple mechanisms of action, of which not all involve alteration in histone acetylation. But it is apparent that butyrate modulates transcriptional regulation in a similar manner as other HDAC inhibitors do, with similar consequences concerning cellular differentiation, cell cycle arrest, apoptosis, invasion and metastasis. Like other HDAC inhibitors, butyrate is able to induce apoptosis by a mechanism involving the activation of caspases and decreased levels of Bcl-2 [91]. Apoptosis mediated by activation of death receptors has also been proposed for butyrate, with increasing death receptor 5 (DR5) expression, a receptor for TRAIL, consequently leading to activation of caspase 8 and caspase 10 [92]. Additionally, butyrate inhibits tumor invasion and metastasis, as it induces expression of proteins that are known to inhibit invasion in a cell culture model [93] and reduced liver metastasis of rat colon cancer cells in vivo and resistance to oxidative stress in vitro [94]. Although therapeutic intervention with butyrate is not promising, an ongoing exposure stemming from the microbial degradation of dietary fiber in the colon could have chemopreventive effects, at least in part by histone deacetylase inhibition [95]. Ester prodrugs of butyrates might have potential for an improvement of fatty acid based HDAC inhibitors [96].

Diallyl disulfide (DADS) is an organosulfur compound, which is found in garlic and other Allium species. Upon administration of DADS, differentiation, cell cycle arrest and apoptosis has been demonstrated in several cell lines [97], for example, by inducing a G2/M arrest in different cancer cell types, such as colon and neuroblastoma cells and by increasing the expression levels of BAX in human lung and breast cancer cells [98], [99]. S-Allylmercaptocysteine, a metabolite of DADS, has also been shown to have an effect on the levels of histone acetylation. It induced growth arrest in human colon and breast cancer cells [100] and also a G2/M arrest, as well as apoptosis in human colon cells has been described [101]. Inhibition of histone deacetylases seems to be a general mechanism for cancer prevention by organosulfur agents from garlic or other Allium vegetables. Sulforaphane (SFN), an isothiocyanate present in cruciferous vegetables, such 
as broccoli, has been made responsible for several chemopreventive mechanisms [102]. For example, SFN increases histone H4 acetylation in P21 promoter regions, subsequently leading to an increasing expression of p21 in HCT116 cells. In addition, the higher acetylation levels achieved by SFN led to G2/M arrest [103] and apoptosis. Remarkably, the metabolite SFN-cysteine and not the parent compound itself, is the active, HDAC-inhibiting principle. [104]. Interestingly, it was demonstrated that a combination of sulforaphane and the DMNT-inhibiting isoflavone genistein enhances the reactivation of the DNA methylation-silenced genes p16INK4a and MGMT [55], implicating synergistic effects. Recently, ACS 2, a sulfurated derivative of valproic acid (VPA), has been demonstrated to show HDAC inhibition [105]. It displayed much stronger inhibition of deacetylase activity than VPA, which is also known as an HDAC inhibitor. Also its sulfur containing moiety, 5-(4-hydroxyphenyl)-3H-1,2-dithiole3-thione, a metabolite of anethole trithione is contributing to this inhibition of HDACs. Anethole trithione has shown potential in clinical trials for lung cancer prevention [106]. Inhibition of sirtuins has been shown for hyperforin and derivatives [107] but it is unclear whether the antiproliferative activity of these compounds can be tied to sirtuin inhibition. Resveratrol, a polyphenol from grapes, has received a lot of attention in cancer chemoprevention [108]. It has been postulated to be an activator of sirtuins [109] but there is discussion about whether these effects are artefacts from the assay procedure [110]. Sirtuin activators have demonstrated anti-inflammatory effects, e.g., decreased release of TNF- $\alpha$, that make them interesting for the prevention of damages by metabolic diseases [111], [112] which could also play a role for cancer chemoprevention. But again, it will be difficult to dissect the decisive effects for such an activity in a pleiotropic drug like resveratrol.

\section{Inhibition of histone acetyltransferases}

Although direct cancer prevention of specific modulators of histone acetyltransferases has not been demonstrated so far, they have shown their capability in cancer therapy, as they are involved in transcriptional regulation. Several studies support the assumption that HATs, such as p300/CBP, act as transcriptional integrators for physiological cues to coordinate regulation of cell cycle, differentiation, DNA repair and apoptosis [113], [114]. Taking the inhibitors of HDACs as an example, it is possible that HAT inhibitors have potential in cancer prevention as well.

Different types of inhibitors of histone acetyltransferases have been reported and also several natural products have shown their ability to inhibit HATs. For example, anacardic acid, found in the apple of the cashew (Anacardium occidentale), shows antitumor activity due to an inhibition of p300 and PCAF in the low micromolar range [115], [116], with the problem, however, that cells are poorly permeable for this compound. Garcinol, a polyisoprenylated benzophenone derivative from Garcinia indica fruit rind, has been described as a cell-permeable HAT inhibitor, showing inhibition towards p300 and PCAF [117]. Another natural compound, which has been shown to specifically inhibit p300/CPB, is curcumin, a major curcuminoid in turmeric [118]. But again, curcumin is a pleiotropic agent with numerous possible mechanisms that could contribute to a chemopreventive effect [48].

Ursodeoxycholic acid (UDCA, ursodiol), a tertiary bile acid used in treatment of biliary cirrhosis and ulcerative colitis has been demonstrated to have potential in colon cancer prevention in preclinical and in animal models [119], [120], but the mecha- nisms behind it were unknown. Recently, it has been shown that UDCA induces differentiation and senescence by modulating histone acetylation [121]. But in contrast to HDAC inhibitors, UDCA induces hypoacetylation of histones like HAT inhibitors would do, although histone acetylase activity is not affected directly by UDCA in vitro. Further investigation revealed that HDAC6 is up-regulated in cells treated with ursodeoxycholic acid [121]. Not only because of this finding has it already been suggested that modulation of HAT or HDAC activity in any direction might induce differentiation and senescence [121]. At present, a randomized phase II clinical trial is ongoing, comparing UDCA to acetylsalicylic acid or sulindac for its activity in preventing colorectal cancer [122].

\section{Modulation of histone methylation}

Histone methylation is another widely described modification, taking place at lysine and arginine residues. Histone methylation marks play a role in regulation of transcriptional activity as well. Methylation of histones, for example, has been shown to be important for the establishment of a checkpoint control following DNA damage [123]. The methylation of arginine residues contributes to both transcriptionally active and repressed genes and is catalyzed by protein arginine methyltransferases (PRMTs) [124], [125], [126]. Arginine methylation generally is correlated with transcriptional activation and can occur in three different states, monomethylated, symmetrically dimethylated or asymmetrically dimethylated. PADI4, a peptidyldeiminase is able to remove methyl groups from methylated arginines, leading to citrulline [127]. But because of the fact that unmethylated arginines are deiminated to citrullines as well, the role of PADI4 in antagonizing histone arginine methylation needs further clarification. Nevertheless, it is clear that demethylimination of arginines contributes to regulation of transcription. Importantly, PADI4 is not able to demethylate dimethylated arginines. Recently, a new enzyme with arginine demethylase activity has been discovered [128]. This Jumanji domain-containing protein 6 (JMJD6) is an iron- and $\alpha$-ketoglutarate-dependent dioxygenase that demethylates histone H3 at arginine 2 (H3R2) and histone 4 at arginine 3 (H4R3). In contrast to the deiminase PADI4, JMJD6 is able to remove methyl groups from dimethylated arginines [128].

The methylation of lysine residues can lead either to activation or repression of gene expression, depending on the particular histone lysine residue [36]. Methylation of H3K4, H3K36 and H3K79 are associated with transcriptional activation [129], whereas methylation of H3K9, H3K27 and H4K20 are linked to repressed genes [130]. As mentioned above, also the methylation state (mono-, di- or trimethylation) is variable, having different effects on transcription [37]. Histone lysine methylation is carried out by a family of proteins containing a SET (suppressor of variegation, enhancer of zeste and trithorax) domain and by the non-SET-domain proteins DOT1/DOT1 L [131], [132]. All lysine methyltransferases use $S$-adenosyl-L-methionine (SAM) as the cofactor. Until recently, it was assumed that histone lysine methylation was an irreversible modification, although a group led by Paik had described a demethylating activity in rat kidney already in 1964 [133]. But this activity was never linked to a particular enzyme. In 2004, the assumption of "permanent methylation" really was shaken, when the lysine specific demethylase 1 (LSD1), known as a component of several histone deacetylase complexes, was identified as an amine oxidase which selectively removes methyl groups from H3K4 (mono- or dimethylated) 
[134]. Interestingly, LSD1 can change its selectivity to H3K9 (mono- or dimethylated) when it interacts with the androgen receptor [135]. Caused by its monoamine oxidase (MAO) type mechanism of the demethylation reaction, LSD1 is not able to demethylate trimethylated lysine residues. Hence it was assumed that there have to be demethylases that operate by a different mechanism. An oxidation reaction similar to that of AlkB from $E$. coli, a demethylating DNA repair enzyme was predicted [136]. AlkB is a $\alpha$-ketoglutarate- and iron-dependent dioxygenase which hydroxylates methyl groups from damaged DNA leading to the release of formaldehyde. In search for histone lysine demethylating enzymes with a similar mechanism, the group of the already mentioned Jumanji domain-containing (JmjC) enzymes was identified [137]. In fact, the members of this family are able to demethylate trimethylated lysine residues in an oxidation reaction also dependent on Fe(II) and $\alpha$-ketoglutarate.

So far, only few small molecule modulators of the histone lysine demethylating enzymes have been described. But evidence suggests that LSD1 is a promising target both in cancer prevention and in therapy. It is up-regulated in mammary epithelial cells that have been exposed to dietary and environmental carcinogens, resulting in the assumption that induction of LSD1 represents an early response to carcinogen exposure [138]. It has also been reported that inhibition of LSD1 in colon carcinoma cells results in re-expression of aberrantly silenced genes, which are important in the development of colon cancer [139]. The colocalization of LSD1 and the androgen receptor in androgen-dependent tissue led to investigations showing that LSD1 stimulates androgen-receptor-dependent transcription [135]. JMJD2C, a member of the Jumanji domain-containing enzymes has been reported to regulate the androgen receptor as well [140]. It was found that JMJD2C colocalizes with LSD1 and the androgen receptor and that both demethylases cooperatively stimulate androgen receptor-dependent gene expression [140]. Thus, modulation of the activity of LSD1 and JMJD2C represents novel strategies to regulate androgen receptor functions and accordingly control specific gene expression. Therefore, the inhibition of LSD1 and the JmjC proteins will be interesting options in cancer prevention and therapy.

\section{Perspectives}

$\nabla$

Epigenetics is an emerging field in cancer research, as the impact of DNA methylation and histone modifications on transcriptional activity is becoming more and more clear. Thus, the search for agents that target these mechanisms in order to elucidate the role of DNA methyltransferases and histone modifying enzymes in cancer development is being pursued with increasing efforts. Natural products can be important tools to further characterize the chromatin-modifying enzymes. In many cases they are the first agents identified as inhibitors or modulators of the particular enzyme and thereby serve as lead structures for new druglike compounds or may be drug candidates themselves.

In this review we have presented natural products that target epigenetic mechanisms, more precisely inhibitors of DNA methylation and modulators of histone acetylation and histone methylation. But as mentioned above, there are other modifications to histones, such as ubiquitinylation [141], sumoylation [142] and poly-ADP-ribosylation [143] which have already been associated with altered transcription as well. Natural and chemical prod- ucts acting as novel small molecule inhibitors of the enzymes involved in these modifications will help us to further improve our understanding of the epigenetic mechanisms on the whole and may result in new candidates for cancer prevention and therapy.

\section{References}

1 Crick F. Central dogma of molecular biology. Nature 1970; 227: 561 -3

2 Smith LT, Otterson GA, Plass C. Unraveling the epigenetic code of cancer for therapy. Trends Genet 2007; 23: 449-56

3 Wolffe AP, Matzke MA. Epigenetics: regulation through repression. Science 1999; 286: 481 -6

4 McCabe DC, Caudill MA. DNA methylation, genomic silencing, and links to nutrition and cancer. Nutr Rev 2005; 63: 183 - 95

5 Bird A. DNA methylation patterns and epigenetic memory. Genes Dev 2002; 16: 6-21

6 Ehrlich M, Gama-Sosa MA, Huang LH, Midgett RM, Kuo KC, McCune RA et al. Amount and distribution of 5-methylcytosine in human DNA from different types of tissues of cells. Nucleic Acids Res 1982; 10: $2709-21$

7 Takai D, Jones PA. Comprehensive analysis of CpG islands in human chromosomes 21 and 22. Proc Natl Acad Sci U S A 2002; 99: 3740 - 5

8 Gardiner-Garden M, Frommer M. CpG islands in vertebrate genomes. J Mol Biol 1987; 196: 261 - 82

9 Dunn BK. Hypomethylation: one side of a larger picture. Ann N Y Acad Sci 2003; 983: 28-42

10 Baylin SB, Herman JG. DNA hypermethylation in tumorigenesis: epigenetics joins genetics. Trends Genet 2000; 16: $168-74$

11 Costello JF, Plass C. Methylation matters. J Med Genet 2001; 38: 285 303

12 Esteller $\mathrm{M} . \mathrm{CpG}$ island hypermethylation and tumor suppressor genes: a booming present, a brighter future. Oncogene 2002; 21: 5427-40

13 Brannan CI, Bartolomei MS. Mechanisms of genomic imprinting. Curr Opin Genet Dev 1999; 9: 164 - 70

14 Hansen RS. X inactivation-specific methylation of LINE-1 elements by DNMT3B: implications for the Lyon repeat hypothesis. Hum Mol Genet $2003 ; 12: 2559-67$

15 Li E, Bestor TH, Jaenisch R. Targeted mutation of the DNA methyltransferase gene results in embryonic lethality. Cell 1992; 69: 915-26

16 Ateeq B, Unterberger A, Szyf M, Rabbani SA. Pharmacological inhibition of DNA methylation induces proinvasive and prometastatic genes in vitro and in vivo. Neoplasia 2008; 10: $266-78$

17 Bestor T, Laudano A, Mattaliano R, Ingram V. Cloning and sequencing of a cDNA encoding DNA methyltransferase of mouse cells. The carboxyl-terminal domain of the mammalian enzymes is related to bacterial restriction methyltransferases. J Mol Biol 1988; 203: 971 - 83

18 Yoder JA, Bestor TH. A candidate mammalian DNA methyltransferase related to pmt1 p of fission yeast. Hum Mol Genet 1998; 7: 279-84

19 Okano M, Xie S, Li E. Cloning and characterization of a family of novel mammalian DNA (cytosine-5) methyltransferases. Nat Genet 1998; 19: $219-20$

20 Wu J, Grunstein M. 25 years after the nucleosome model: chromatin modifications. Trends Biochem Sci 2000; 25: 619-23

21 Luger K, Mader AW, Richmond RK, Sargent DF, Richmond TJ. Crystal structure of the nucleosome core particle at 2.8 A resolution. Nature 1997; 389: $251-60$

22 Tremethick DJ. Higher-order structures of chromatin: the elusive $30 \mathrm{~nm}$ fiber. Cell 2007; 128: 651 - 4

23 Jenuwein T, Allis CD. Translating the histone code. Science 2001; 293: $1074-80$

24 Berger SL. The complex language of chromatin regulation during transcription. Nature 2007; 447: 407-12

25 Kouzarides T. Chromatin modifications and their function. Cell 2007; 128: $693-705$

26 Rodenhiser D, Mann M. Epigenetics and human disease: translating basic biology into clinical applications. Cmaj 2006; 174: 341 - 8

27 Li B, Carey M, Workman JL. The role of chromatin during transcription. Cell 2007; 128: 707-19

28 Nan X, Ng HH, Johnson CA, Laherty CD, Turner BM, Eisenman RN et al. Transcriptional repression by the methyl-CpG-binding protein MeCP2 involves a histone deacetylase complex. Nature 1998; 393: 386-9

29 Jones PL, Veenstra GJ, Wade PA, Vermaak D, Kass SU, Landsberger $N$ et al. et alMethylated DNA and MeCP2 recruit histone deacetylase to repress transcription. Nat Genet 1998; 19: 187-91 
30 Zhu WG, Otterson GA. The interaction of histone deacetylase inhibitors and DNA methyltransferase inhibitors in the treatment of human cancer cells. Curr Med Chem Anticancer Agents 2003; 3: 187 - 99

31 Cameron EE, Bachman KE, Myohanen S, Herman JG, Baylin SB. Synergy of demethylation and histone deacetylase inhibition in the re-expression of genes silenced in cancer. Nat Genet 1999; 21: $103-7$

32 Kikuchi T, Itoh F, Toyota M, Suzuki H, Yamamoto H, Fujita M et al. Aberrant methylation and histone deacetylation of cyclooxygenase 2 in gastric cancer. Int J Cancer 2002; 97: 272 - 7

33 Jones PA, Baylin SB. The fundamental role of epigenetic events in cancer. Nat Rev Genet 2002; 3: 415 - 28

34 Cheung $P$, Lau $P$. Epigenetic regulation by histone methylation and histone variants. Mol Endocrinol 2005; 19: 563 - 73

35 Rossig L, Li H, Fisslthaler B, Urbich C, Fleming I, Forstermann U et al. Inhibitors of histone deacetylation downregulate the expression of endothelial nitric oxide synthase and compromise endothelial cell function in vasorelaxation and angiogenesis. Circ Res 2002; 91: 837 - 44

36 Kouzarides $T$. Histone methylation in transcriptional control. Curr Opin Genet Dev 2002; 12: 198 - 209

37 Lachner M, Sengupta R, Schotta G, Jenuwein T. Trilogies of histone lysine methylation as epigenetic landmarks of the eukaryotic genome. Cold Spring Harb Symp Quant Biol 2004; 69: 209-18

38 Fraga MF, Ballestar E, Villar-Garea A, Boix-Chornet M, Espada J, Schotta $G$ et al. Loss of acetylation at Lys 16 and trimethylation at Lys20 of histone H4 is a common hallmark of human cancer. Nat Genet 2005; 37: $391-400$

39 Metzger E, Yin N, Wissmann M, Kunowska N, Fischer K, Friedrichs $N$ et al. Phosphorylation of histone $\mathrm{H} 3$ at threonine 11 establishes a novel chromatin mark for transcriptional regulation. Nat Cell Biol 2008; 10: $53-60$

40 Christman JK. 5-Azacytidine and 5-aza-2'-deoxycytidine as inhibitors of DNA methylation: mechanistic studies and their implications for cancer therapy. Oncogene 2002; 21: 5483-95

41 Jones PA, Taylor SM. Cellular differentiation, cytidine analogs and DNA methylation. Cell 1980; 20: 85 - 93

42 Laird PW, Jackson-Grusby L, Fazeli A, Dickinson SL, Jung WE, Li E et al. Suppression of intestinal neoplasia by DNA hypomethylation. Cell 1995; 81: $197-205$

43 Davis $C D$, Uthus EO. Dietary selenite and azadeoxycytidine treatments affect dimethylhydrazine-induced aberrant crypt formation in rat colon and DNA methylation in HT-29 cells. J Nutr 2002; 132: 292 - 7

44 Lantry LE, Zhang Z, Crist KA, Wang Y, Kelloff GJ, Lubet RA et al. 5-Aza-2'deoxycytidine is chemopreventive in a 4-(methyl-nitrosamino)-1-(3pyridyl)-1-butanone-induced primary mouse lung tumor model. Carcinogenesis 1999; 20: $343-6$

45 McGregor F, Muntoni A, Fleming J, Brown J, Felix DH, MacDonald DG et al. Molecular changes associated with oral dysplasia progression and acquisition of immortality: potential for its reversal by 5 -azacytidine. Cancer Res 2002; 62: 4757-66

46 Pina IC, Gautschi JT, Wang GY, Sanders ML, Schmitz FJ, France D et al. Psammaplins from the sponge Pseudoceratina purpurea: inhibition of both histone deacetylase and DNA methyltransferase. J Org Chem 2003; 68: 3866 - 73

47 Fang MZ, Wang Y, Ai N, Hou Z, Sun Y, Lu H et al. Tea polyphenol (-)-epigallocatechin-3-gallate inhibits DNA methyltransferase and reactivates methylation-silenced genes in cancer cell lines. Cancer Res 2003; 63: $7563-70$

48 Narayanan $B A$. Chemopreventive agents alters global gene expression pattern: predicting their mode of action and targets. Curr Cancer Drug Targets 2006; 6: $711-27$

49 Lee WJ, Zhu BT. Inhibition of DNA methylation by caffeic acid and chlorogenic acid, two common catechol-containing coffee polyphenols. Carcinogenesis 2006; 27: 269-77

50 Fini L, Selgrad M, Fogliano V, Graziani G, Romano M, Hotchkiss E et al. Annurca apple polyphenols have potent demethylating activity and can reactivate silenced tumor suppressor genes in colorectal cancer cells. J Nutr 2007; 137: 2622 -8

51 Dixon RA, Ferreira D. Genistein. Phytochemistry 2002; 60: 205-11

52 Dean NM, Kanemitsu M, Boynton AL. Effects of the tyrosine-kinase inhibitor genistein on DNA synthesis and phospholipid-derived second messenger generation in mouse 10T1/2 fibroblasts and rat liver T51B cells. Biochem Biophys Res Commun 1989; 165: 795 - 801

53 Wietrzyk J, Boratynski J, Grynkiewicz G, Ryczynski A, Radzikowski C, Opolski A. Antiangiogenic and antitumour effects in vivo of genistein applied alone or combined with cyclophosphamide. Anticancer Res $2001 ; 21: 3893-6$

54 Shao ZM, Wu J, Shen ZZ, Barsky SH. Genistein exerts multiple suppressive effects on human breast carcinoma cells. Cancer Res 1998; 58 : $4851-7$

55 Fang MZ, Chen D, Sun Y, Jin Z, Christman JK, Yang CS. Reversal of hypermethylation and reactivation of p16INK4a, RARbeta, and MGMT genes by genistein and other isoflavones from soy. Clin Cancer Res 2005; 11 : $7033-41$

56 Allfrey VG, Faulkner R, Mirsky AE. Acetylation and methylation of histones and their possible role in the regulation of RNA synthesis. Proc Natl Acad Sci U S A 1964; 51: 786 - 94

57 Roth SY, Denu JM, Allis CD. Histone acetyltransferases. Annu Rev Biochem 2001; 70: $81-120$

58 Yang XJ, Seto E. The Rpd3/Hda1 family of lysine deacetylases: from bacteria and yeast to mice and men. Nat Rev Mol Cell Biol 2008; 9: $206-18$

59 Taunton J, Hassig CA, Schreiber SL. A mammalian histone deacetylase related to the yeast transcriptional regulator Rpd3p. Science 1996; 272: $408-11$

60 Gao L, Cueto MA, Asselbergs F, Atadja P. Cloning and functional characterization of HDAC11, a novel member of the human histone deacetylase family. J Biol Chem 2002; 277: 25748 - 55

61 Gregoretti IV, Lee YM, Goodson HV. Molecular evolution of the histone deacetylase family: functional implications of phylogenetic analysis. J Mol Biol 2004; 338: 17 - 31

62 Gray SG, Ekstrom TJ. The human histone deacetylase family. Exp Cell Res 2001; 262: 75-83

63 Haggarty SJ, Koeller KM, Wong JC, Grozinger CM, Schreiber SL. Domainselective small-molecule inhibitor of histone deacetylase 6 (HDAC6)mediated tubulin deacetylation. Proc Natl Acad Sci U S A 2003; 100 : 4389-94

64 Smith JS, Avalos J, Celic I, Muhammad S, Wolberger C, Boeke JD. SIR2 family of $\mathrm{NAD}(+)$-dependent protein deacetylases. Methods Enzymo 2002; 353: $282-300$

65 Dryden SC, Nahhas FA, Nowak JE, Goustin AS, Tainsky MA. Role for human SIRT2 NAD-dependent deacetylase activity in control of mitotic exit in the cell cycle. Mol Cell Biol 2003; 23: 3173-85

66 Bereshchenko OR, Gu W, Dalla-Favera $R$. Acetylation inactivates the transcriptional repressor BCL6. Nat Genet 2002; 32: 606-13

67 Smith J. Human Sir2 and the 'silencing' of p53 activity. Trends Cell Biol 2002; $12: 404-6$

68 Jung M, Hoffmann K, Brosch G, Loidl P. Analogues of trichostatin A and trapoxin B as histone deacetylase inhibitors. Bioorg Med Chem Lett 1997; 7: $1655-8$

69 Finnin MS, Donigian JR, Cohen A, Richon VM, Rifkind RA, Marks PA et al. Structures of a histone deacetylase homologue bound to the TSA and SAHA inhibitors. Nature 1999; 401: 188-93

70 Marks PA, Richon VM, Rifkind RA. Histone deacetylase inhibitors: inducers of differentiation or apoptosis of transformed cells. J Natl Cancer Inst 2000; 92: 1210-6

71 Johnstone RW. Histone-deacetylase inhibitors: novel drugs for the treatment of cancer. Nat Rev Drug Discov 2002; 1: 287-99

72 Yoshida M, Kijima M, Akita M, Beppu T. Potent and specific inhibition of mammalian histone deacetylase both in vivo and in vitro by trichostatin A. J Biol Chem 1990; 265: 17174 - 9

73 Mork CN, Faller DV, Spanjaard RA. A mechanistic approach to anticancer therapy: targeting the cell cycle with histone deacetylase inhibitors. Curr Pharm Des 2005; 11: 1091 - 104

74 McLaughlin F, La Thangue NB. Histone deacetylase inhibitors open new doors in cancer therapy. Biochem Pharmacol 2004; 68: 1139-44

75 Emionite L, Galmozzi F, Grattarola M, Boccardo F, Vergani L, Toma S. Histone deacetylase inhibitors enhance retinoid response in human breast cancer cell lines. Anticancer Res 2004; 24: 4019-24

76 Taddei A, Roche D, Bickmore WA, Almouzni G. The effects of histone deacetylase inhibitors on heterochromatin: implications for anticancer therapy? EMBO Rep 2005; 6: 520-4

77 Ungerstedt JS, Sowa Y, Xu WS, Shao Y, Dokmanovic M, Perez G et al. Role of thioredoxin in the response of normal and transformed cells to histone deacetylase inhibitors. Proc Natl Acad Sci USA 2005; 102: 673 -8

78 Nebbioso A, Clarke N, Voltz E, Germain E, Ambrosino C, Bontempo P et al. Tumor-selective action of HDAC inhibitors involves TRAIL induction in acute myeloid leukemia cells. Nat Med 2005; 11: $77-84$

79 Glick RD, Swendeman SL, Coffey DC, Rifkind RA, Marks PA, Richon VM et al. Hybrid polar histone deacetylase inhibitor induces apoptosis and 
CD95/CD95 ligand expression in human neuroblastoma. Cancer Res 1999; 59: $4392-9$

80 Kwon SH, Ahn SH, Kim YK, Bae GU, Yoon JW, Hong S et al. Apicidin, a histone deacetylase inhibitor, induces apoptosis and Fas/Fas ligand expression in human acute promyelocytic leukemia cells. J Biol Chem 2002; 277: $2073-80$

81 Cohen LA, Amin S, Marks PA, Rifkind RA, Desai D, Richon VM. Chemoprevention of carcinogen-induced mammary tumorigenesis by the hybrid polar cytodifferentiation agent, suberanilohydroxamic acid (SAHA). Anticancer Res 1999; 19: 4999-5005

82 Cohen LA, Marks PA, Rifkind RA, Amin S, Desai D, Pittman B et al. Suberoylanilide hydroxamic acid (SAHA), a histone deacetylase inhibitor, suppresses the growth of carcinogen-induced mammary tumors. Anticancer Res 2002; 22: 1497-504

83 Desai D, Das A, Cohen L, el-Bayoumy K, Amin S. Chemopreventive efficacy of suberoylanilide hydroxamic acid (SAHA) against 4-(methylnitrosamino)-1-(3-pyridyl)-1-butanone (NNK)-induced lung tumorigenesis in female A/J mice. Anticancer Res 2003; 23: 499-503

84 Mann BS, Johnson JR, Cohen MH, Justice R, Pazdur R. FDA approval summary: vorinostat for treatment of advanced primary cutaneous T-cell lymphoma. Oncologist 2007; 12: 1247 - 52

85 Kim MS, Kwon HJ, Lee YM, BaekJH, Jang JE, Lee SW et al. Histone deacetylases induce angiogenesis by negative regulation of tumor suppressor genes. Nat Med 2001; 7: 437-43

$86 \mathrm{Kim}$ DH, Kim M, Kwon HJ. Histone deacetylase in carcinogenesis and its inhibitors as anti-cancer agents. J Biochem Mol Biol 2003; 36: $110-9$

87 Budillon A, Di Gennaro E, Bruzzese F, Rocco M, Manzo G, Caraglia M. Histone deacetylase inhibitors: a new wave of molecular targeted anticancer agents. Recent Patents Anticancer Drug Discov 2007; 2: 119 34

88 Glaser KB. HDAC inhibitors: Clinical update and mechanism-based potential. Biochem Pharmacol 2007; 74: 659-71

89 Scheppach W, Bartram HP, Richter F. Role of short-chain fatty acids in the prevention of colorectal cancer. Eur J Cancer 1995; 31A: 1077 - 80

90 Scheppach $W$, Weiler $F$. The butyrate story: old wine in new bottles? Curr Opin Clin Nutr Metab Care 2004; 7: 563 - 7

91 Hinnebusch BF, Meng S, Wu JT, Archer SY, Hodin RA. The effects of short-chain fatty acids on human colon cancer cell phenotype are associated with histone hyperacetylation. J Nutr 2002; 132: 1012 - 7

92 Nakata S, Yoshida T, Horinaka M, Shiraishi T, Wakada M, Sakai T. Histone deacetylase inhibitors upregulate death receptor 5/TRAIL-R2 and sensitize apoptosis induced by TRAIL/APO2-L in human malignant tumor cells. Oncogene 2004; 23: 6261 - 71

93 Emenaker NJ, Calaf GM, Cox D, Basson MD, Qureshi N. Short-chain fatty acids inhibit invasive human colon cancer by modulating UPA, TIMP1, TIMP-2, mutant p53, Bcl-2, Bax, p21 and PCNA protein expression in an in vitro cell culture model. J Nutr 2001; 131: 3041s-6s

94 Li X, Mikkelsen IM, Mortensen B, Winberg JO, Huseby NE. Butyrate reduces liver metastasis of rat colon carcinoma cells in vivo and resistance to oxidative stress in vitro. Clin Exp Metastasis 2004; 21: 331 -8

95 Myzak MC, Dashwood RH. Histone deacetylases as targets for dietary cancer preventive agents: lessons learned with butyrate, diallyl disulfide, and sulforaphane. Curr Drug Targets 2006; 7: 443-52

96 Pouillart PR. Role of butyric acid and its derivatives in the treatment of colorectal cancer and hemoglobinopathies. Life Sci 1998; 63: 173960

97 Herman-Antosiewicz A, Singh SV. Signal transduction pathways leading to cell cycle arrest and apoptosis induction in cancer cells by Allium vegetable-derived organosulfur compounds: a review. Mutat Res 2004; 555: 121 - 31

98 Hong YS, Ham YA, Choi JH, Kim J. Effects of allyl sulfur compounds and garlic extract on the expression of Bcl-2, Bax, and p53 in non small cell lung cancer cell lines. Exp Mol Med 2000; 32: 127 - 34

99 Nakagawa H, Tsuta K, Kiuchi K, Senzaki H, Tanaka K, Hioki K et al. Growth inhibitory effects of diallyl disulfide on human breast cancer cell lines. Carcinogenesis 2001; 22: 891 - 7

100 Lea MA, Rasheed M, Randolph VM, Khan F, Shareef A, desBordes C. Induction of histone acetylation and inhibition of growth of mouse erythroleukemia cells by S-allylmercaptocysteine. Nutr Cancer 2002; 43: $90-102$

101 Shirin H, Pinto JT, Kawabata Y, Soh JW, Delohery T, Moss SF et al. Antiproliferative effects of S-allylmercaptocysteine on colon cancer cells when tested alone or in combination with sulindac sulfide. Cancer Res 2001; 61: $725-31$
102 Myzak MC, Hardin K, Wang R, Dashwood RH, Ho E. Sulforaphane inhibits histone deacetylase activity in $\mathrm{BPH}-1, \mathrm{LnCaP}$ and $\mathrm{PC}-3$ prostate epithelial cells. Carcinogenesis 2006; 27: 811 -9

103 Qiu L, Burgess A, Fairlie DP, Leonard H, Parsons PG, Gabrielli BG. Histone deacetylase inhibitors trigger a G2 checkpoint in normal cells that is defective in tumor cells. Mol Biol Cell 2000; 11: 2069-83

104 Myzak MC, Karplus PA, Chung FL, Dashwood RH. A novel mechanism of chemoprotection by sulforaphane: inhibition of histone deacetylase. Cancer Res 2004; 64: 5767 - 74

105 Perrino E, Cappelletti G, Tazzari V, Giavini E, Del Soldato P, Sparatore A. New sulfurated derivatives of valproic acid with enhanced histone deacetylase inhibitory activity. Bioorg Med Chem Lett 2008; 18: $1893-7$

106 Lam S, MacAulay C, Le Riche JC, Dyachkova Y, Coldman A, Guillaud M et al. A randomized phase IIb trial of anethole dithiolethione in smokers with bronchial dysplasia. J Natl Cancer Inst 2002; 94: 1001 - 9

107 Gey C, Kyrylenko S, Hennig L, Nguyen LH, Buttner A, Pham HD et al. Phloroglucinol derivatives guttiferone $\mathrm{G}$, aristoforin, and hyperforin: inhibitors of human sirtuins SIRT1 and SIRT2. Angew Chem Int Ed Engl 2007; 46: 5219-22

108 Shankar S, Singh G, Srivastava RK. Chemoprevention by resveratrol: molecular mechanisms and therapeutic potential. Front Biosci 2007; $12: 4839-54$

109 Howitz KT, Bitterman KJ, Cohen HY, Lamming DW, Lavu S, Wood JG et al. Small molecule activators of sirtuins extend Saccharomyces cerevisiae lifespan. Nature 2003; 425: 191 - 6

110 Borra MT, Smith BC, Denu JM. Mechanism of human SIRT1 activation by resveratrol. J Biol Chem 2005; 280: 17187 - 95

111 Nayagam VM, Wang X, Tan YC, Poulsen A, Goh KC, Ng T et al. SIRT1 modulating compounds from high-throughput screening as anti-inflammatory and insulin-sensitizing agents. J Biomol Screen 2006; 11: $959-67$

112 Lagouge M, Argmann C, Gerhart-Hines Z, Meziane H, Lerin C, Daussin F et al. Resveratrol improves mitochondrial function and protects against metabolic disease by activating SIRT1 and PGC-1alpha. Cell 2006; 127: 1109-22

113 Shikama N, Lyon J, LaThangue NB. The p300/CBP family: Integrating signals with transcription factors and chromatin. Trends Cell Biol 1997: 7: $230-6$

114 Giles RH, Peters DJM, Breuning $M H$. Conjunction dysfunction: CBP p300 in human disease. Trends Genet 1998; 14: 178-83

115 Kubo I, Ochi M, Vieira PC, Komatsu S. Antitumor agents from the cashew (Anacardium occidentale) apple juice. J Agric Food Chem 1993; 41: $1012-5$

116 Balasubramanyam K, Swaminathan V, Ranganathan A, Kundu TK. Small molecule modulators of histone acetyltransferase p300. J Biol Chem 2003; 278: $19134-40$

117 Varier RA, Swaminathan V, Balasubramanyam K, Kundu TK. Implications of small molecule activators and inhibitors of histone acetyltransferases in chromatin therapy. Biochem Pharmacol 2004; 68: $1215-20$

118 Balasubramanyam K, Varier RA, Altaf M, Swaminathan V, Siddappa NB, Ranga $U$ et al. Curcumin, a novel p300/CREB-binding protein-specific inhibitor of acetyltransferase, represses the acetylation of histone/ nonhistone proteins and histone acetyltransferase-dependent chromatin transcription. J Biol Chem 2004; 279: 51163 - 71

119 Earnest DL, Holubec H, Wali RK, Jolley CS, Bissonette M, Bhattacharyya $A K$ et al. Chemoprevention of azoxymethane-induced colonic carcinogenesis by supplemental dietary ursodeoxycholic acid. Cancer Res 1994; 54: 5071 - 4

120 Wali RK, Frawley BP Jr, Hartmann S, Roy HK, Khare S, Scaglione-Sewell $B A$ et al. Mechanism of action of chemoprotective ursodeoxycholate in the azoxymethane model of rat colonic carcinogenesis: potential roles of protein kinase C-alpha, -beta II, and -zeta. Cancer Res 1995; 55: $5257-64$

121 Akare S, Jean-Louis S, Chen W, Wood DJ, Powell AA, Martinez JD. Ursodeoxycholic acid modulates histone acetylation and induces differentiation and senescence. Int J Cancer 2006; 119: 2958 - 69

122 Available at http://clinicaltrials.gov/ct2/show/NCT00062023?intr= UDCA\&rank=10. Accessed 2008

123 Huyen Y, Zgheib O, Ditullio RA Jr, Gorgoulis VG, Zacharatos P, Petty TJ et al. Methylated lysine 79 of histone $\mathrm{H} 3$ targets 53BP1 to DNA doublestrand breaks. Nature 2004; 432: 406-11 
124 Wang H, Huang ZQ Xia L, Feng Q Erdjument-Bromage H, Strahl BD et al. Methylation of histone $\mathrm{H} 4$ at arginine 3 facilitating transcriptional activation by nuclear hormone receptor. Science 2001; 293: 853-7

125 Yu MC, Lamming DW, Eskin JA, Sinclair DA, Silver PA. The role of protein arginine methylation in the formation of silent chromatin. Genes Dev 2006; 20: 3249-54

126 Strahl BD, Briggs SD, Brame CJ, Caldwell JA, Koh SS, Ma H et al. Methylation of histone $\mathrm{H} 4$ at arginine 3 occurs in vivo and is mediated by the nuclear receptor coactivator PRMT1. Curr Biol 2001; 11: 996 1000

127 Nakashima K, Hagiwara T, Yamada M. Nuclear localization of peptidylarginine deiminase $\mathrm{V}$ and histone deimination in granulocytes. J Biol Chem 2002; 277: 49562-8

128 Chang B, Chen Y, Zhao Y, Bruick RK. JMJD6 is a histone arginine demethylase. Science 2007; 318: $444-7$

129 Schubeler D, MacAlpine DM, Scalzo D, Wirbelauer C, Kooperberg C, van Leeuwen $\mathrm{F}$ et al. The histone modification pattern of active genes revealed through genome-wide chromatin analysis of a higher eukaryote. Genes Dev 2004; 18: 1263 - 71

130 Peters AH, Kubicek S, Mechtler K, O'Sullivan RJ, Derijck AA, PerezBurgos $L$ et al. Partitioning and plasticity of repressive histone methylation states in mammalian chromatin. Mol Cell 2003; 12: 1577-89

131 Lachner M, O'Sullivan RJ, Jenuwein T. An epigenetic road map for histone lysine methylation. J Cell Sci 2003; 116: 2117-24

132 Margueron $R$, Trojer $P$, Reinberg $D$. The key to development: interpreting the histone code? Curr Opin Genet Dev 2005; 15: 163-76

133 Kim S, Benoiton L, Paik WK. Epsilon-alkyllysinase. Purification and properties of the enzyme. J Biol Chem 1964; 239: 3790-6
134 Shi Y, Lan F, Matson C, Mulligan P, Whetstine JR, Cole PA et al. Histone demethylation mediated by the nuclear amine oxidase homolog LSD1. Cell 2004; 119: 941 - 53

135 Metzger E, Wissmann M, Yin N, Muller JM, Schneider R, Peters AH et al. LSD1 demethylates repressive histone marks to promote androgenreceptor-dependent transcription. Nature 2005; 437: 436 -9

136 Trewick SC, McLaughlin PJ, Allshire RC. Methylation: lost in hydroxylation? EMBO Rep 2005; 6: 315 - 20

137 Tsukada Y, Fang J, Erdjument-Bromage H, Warren ME, Borchers $\mathrm{CH}$, Tempst $P$ et al. Histone demethylation by a family of JmjC domaincontaining proteins. Nature 2006; 439: 811 -6

138 Bradley C, van der Meer R, Roodi N, Yan H, Chandrasekharan MB, Sun ZW et al. Carcinogen-induced histone alteration in normal human mammary epithelial cells. Carcinogenesis 2007; 28: 2184-92

139 Huang Y, Greene E, Murray Stewart T, Goodwin AC, Baylin SB, Woster $P M$ et al. Inhibition of lysine-specific demethylase 1 by polyamine analogues results in reexpression of aberrantly silenced genes. Proc Natl Acad Sci U S A 2007; 104: 8023-8

140 Wissmann M, Yin N, Muller JM, Greschik H, Fodor BD, Jenuwein T et al. Cooperative demethylation by JMJD2C and LSD1 promotes androgen receptor-dependent gene expression. Nat Cell Biol 2007; 9: 347-53

141 Zhang $Y$. Transcriptional regulation by histone ubiquitination and deubiquitination. Genes Dev 2003; 17: 2733 - 40

142 Shiio Y, Eisenman RN. Histone sumoylation is associated with transcriptional repression. Proc Natl Acad Sci U S A 2003; 100: 13225 - 30

143 Niedergang CP, de Murcia G, Ittel ME, Pouyet J, Mandel P. Time course of polynucleosome relaxation and ADP-ribosylation. Correlation between relaxation and histone H1 hyper-ADP-ribosylation. Eur J Biochem 1985; 146: 185 - 91 